alter the behaviour. This may require changing the child's timetable or his room or ward; it may mean more personal contact with a particular relative or a member of staff. When drugs are given their use should be reconsidered at frequent intervals. When hypnotics or sedatives are prescribed to help in a crisis they should be stopped when the crisis is over. When they are used to tide over a period during which alternative management is introduced they should be stopped soon after the introduction of the new regimen. It may then be possible to see if the changes really are in the best interests of the child.

${ }^{1}$ Kirman, B, British fournal of Psychiatry, 1975, 127, 545.

2 Department of Health and Social Security, Census of Mentally Handicapped Patients in Hospitals in England and Wales at the End of 1970. London, HMSO, 1972

${ }^{3}$ Wright, E, Abbas, K A, and Meredith, C, British fournal of Mental Subnormality, 1974, 20, 14

${ }^{4}$ Raynes, N V, and King, R D, in Proceedings of 1st Congress of the International Association for the Scientific Study of Mental Deficiency, 1967, ed B W Richard, p 657. Reigate, Michael Jackson Publishing Co, 1968.

\section{Surgery for epilepsy}

Enough time has passed since the introduction of surgical treatment for temporal lobe epilepsy for a very clear picture to have emerged of the indications, results, and morbidity of the operations. Yet opinion still remains uncertain and medical treatment is often continued in spite of poor control of seizures with their associated morbidity and mortality. Is this due to fear of surgery and uncertainty about the outcome or to difficulty in obtaining the necessary advice?

Recently in an attempt to clarify the situation Jensen ${ }^{1-3}$ has carried out an extensive analysis of the published results of surgery in the treatment of temporal lobe epilepsy based on the results of 2282 resections carried out between 1928 and 1973 . There is almost universal agreement on the conditions (for example, those suggested by Rasmussen ${ }^{4}$ and Falconer ${ }^{5}$ ) which need to be fulfilled before operation should be considered. Firstly, there must have been a failure to respond to a really adequate trial of drug treatment, including monitoring of the blood levels. There must be evidence of a predominantly or wholly unilateral temporal disorder, as shown by inferior or anterior temporal spikes in the electroencephalogram. If these are bilateral they must be at least four times more frequent on the side to be operated upon. The fits must have been established long enough for there to be reasonable certainty that all potentially epileptogenic areas have manifested themselves and that spontaneous regression is unlikely. Finally the patient must have an IQ of at least 60 . Patients with tumours, arteriovenous malformations, or abscesses are excluded from consideration in this context ; their indications for operation are not based on the control of epilepsy alone.

Considering only those series in which these criteria were fulfilled, and in which adequate preoperative and postoperative data were available, Jensen found that $43.6 \%$ of 885 patients were entirely free from seizures after operation. In $18 \%$ the fits were reduced to less than one-quarter of their former incidence, and in a further $16.5 \%$ there were less than half the number of seizures. Analysis of the reports shows rather a wide scatter in the success rates, but a closer look shows that those series in which surgery was limited to a superficial or partial removal of the temporal lobe had fewer successful results than those in which the deeper structures-including parts of the amygdalum, uncus, and hippocampus-were removed. In a recent series Van Buren ${ }^{6}$ found a success rate of only $6 \%$ for partial operations and $50^{\circ}$ o for the total removal. Again, inclusion of patients with bilateral abnormalities also reduces the success rate, as was shown by Bailey ${ }^{7}$ and Bloom ${ }^{8}$ and their co-workers.

The number of patients with psychiatric abnormality varied from one centre to another, but more than $50 \%$ of those who had mental abnormalities preoperatively were improved or returned to normal. Jensen also showed that neither the epileptic nor the psychiatric history affected the outcome of surgery unless there were genetic factors in both parents. If this was so the likelihood of benefit to the fit pattern or the psychiatric outcome was reduced.

The mortality from the operations was under $1 \%$ and the morbidity was low. Persistent hemiparesis occurred in $2.4 \%$ of the 885 patients studied by Jensen and transient hemiparesis in $4.2 \%$, but these proportions have fallen slightly in recent years. Minor visual defects, of which the patient was unaware, were quite common, and a complete homonymous hemianopia occurred in $8.3 \%$. Temporary dysphasia and diplopia did occur, but they did not persist.

A further inquiry was undertaken into the late mortality after operation. The late mortality of $47 \cdot 6$ per 1000 contrasted with an expected mortality of 2.9 per 1000 in a normal population, but the expected mortality in a similar group of Danish epileptic patients not treated surgically would be 59.4 per 1000. Most late deaths were in the group of $16.5 \%$ of patients with less than a $50 \%$ reduction in their fits: $62 \%$ of these deaths were due to epilepsy, while other causes included suicide in $28 \%$ of those who died and who had continued to suffer from their fits after operation. In a Danish investigation by Henriksen et $a l^{9}$ the excess mortality ratio due to suicide among patients with epilepsy was shown to be $300 \%$; it accounted for $20 \%$ of deaths. This is a measure of suffering, and of the need to use every means to prevent it.

Resections of other parts of the cerebral hemispheres for the treatment of epilepsy were shown by Rasmussen ${ }^{10}$ and Feindel ${ }^{11}$ to have a success rate of $30-45 \%$, but the results may be less permanent. Treatment by implanted electrodes and stereotactic lesions has yet to be fully evaluated. But the value of surgery in the treatment of intractable temporal lobe seizures is now clearly established. The presence of demonstrable and eradicable disease is clear. Two-thirds of the patients operated upon will be helped significantly. The prospect of relief should therefore not be denied to those who need it.

\footnotetext{
Jensen, I, Acta Neurologica Scandinavica, 1975, 52, 354.

2 Jensen, I, Acta Neurologica Scandinavica, 1975, 52, 374

3 Jensen, Acta Neurologica Scandinavica, 1975, 52, 381.

- Rasmussen, T, Clinical Neurosurgery, 1969, 16, 288.

${ }^{5}$ Falconer, M A, Neurochirurgia, 1965, 8, 161.

${ }^{6}$ Van Buren, J M, Marsan, C A, and Mutsuga, N, fournal of Neurosurgery, $1975,43,596$.

'Bailey, et al, Research Publications Association for Research in Nervous and Mental Disease, 1953, 31, 341.

${ }^{8}$ Bloom, D, Jasper, H, and Rasmussen, T, Epilepsia (Amsterdam), 1960, 1, 351 .

${ }^{9}$ Henriksen, B, Juul-Jensen, P, and Lund, M, Life Assurance Medicine, ed R D C Brackenridge, p 139. London, Pitman, 1970.

10 Rasmussen, T, Advances in Neurology, ed D Purpura, J K Penry, and R D Walter, vol 8, pp 197 and 207. New York, Raven Press, 1975.

11 Feindel, W, Advances in Neurology, ed D Purpura, J K Penry, and R D Walter, vol 8, p 281. New York, Raven Press, 1975.
} 